\title{
Biochemical and Morpho-Genetic Characterization of Wild and Cultivated Pomegranate (Punica granatum L.)
}

\author{
Nadia Akram ${ }^{1}$, Muhammad Altaf Hussain ${ }^{2 *}$ and Imran Ali $^{2}$ \\ 1. Department of Botany, Mirpur University of Science and Technology (MUST), Bhimber Campus, Bhimber, Azad \\ Kashmir, Pakistan \\ 2. Department of Biotechnology, Mirpur University of Science and Technology (MUST), Mirpur, Azad Kashmir, \\ Pakistan \\ *Corresponding author's email: altaf.bot@ must.edu.pk
}

Citation

Nadia Akram, Muhammad Altaf Hussain and Imran Ali. Biochemical and Morpho-Genetic Characterization of Wild and Cultivated Pomegranate (Punica granatum L.). Pure and Applied Biology. Vol. 4, Issue 4, 2015, pp 636-649. http://dx.doi.org/10.19045/bspab.2015.44024

Received: $15 / 06 / 2015 \quad$ Revised: $16 / 11 / 2015$

Accepted: $25 / 11 / 2015$

\section{Abstract}

Present research was conducted to characterized the cultivated and wild pomegranate on the basis of morphological and biochemical trait. For morphological characterization fruit weight, fruit length, fruit width, peel thickness, number of arils and leaf area were evaluated. The studied parameters fruit weight, fruit length, fruit width, peel thickness, number of arils and leaf area were within the range of 36-215(g), 30-66.9 (mm), 8.45-64.61 (mm), 0.2-4.2( $\mathrm{mm}), 180-490$ and 1.4-9.5 $\left(\mathrm{cm}^{2}\right)$ respectively. Cluster analysis (UPGMA) and Principal Component Analysis (PCA) for morphological trait reflected significant difference between cultivated and wild pomegranate. Biochemical characterization of cultivated and wild pomegranate was investigated through protein banding profile using Sodium Dodecyl Polyacrylamide Gel Electrophoresis (SDSPAGE). For this purpose, the protein marker of 10-220 kDa (Novex by life technologies) were used to assess the protein polymorphisms within wild and cultivated species of pomegranate and clarify the genetic nature of polymorphic bands. On the basis of banding pattern, electrophorogram were sketched by which molecular weight of species specific band were calculated. The results showed that both wild and cultivated pomegranate conferred genetic diversity and depicted low level of heterogeneity.

Key words: Morphological traits; Protein marker; Wild and cultivated pomegranate; Cluster analysis.

\section{Introduction}

Punica granatum locally known as anaar and belong to family Punicaceae with $2 \mathrm{n}=$ 16 chromosomes. The genus Punica comprises of two species $P$. protopunica and $P$. granatum [1]. Pomegranate (Punica granatum L.) is a spiritual and highly distinguished fruit, declared in the Quran, the Bible, the Jewish Torah [2, 3, 4]. It is considered that pomegranate is the one of the first plant that has been sophisticated by man with olive, grapes and fig [3]. Pomegranate is up to $6 \mathrm{~m}$ tall deciduous small tree and sometimes spiny. Leaves are oblong - lanceolate, $7 \mathrm{~cm}$ long, entire, glabrous and glossy and arranged in 
opposite manner. Flowers are bisexual, $4 \mathrm{~cm}$ across, solitary or clustered at ends of branchlets. Shape of fruit is berry, when it mature color is yellowish green or shiny reddish [5]. The pomegranate was originated in central Asia particularly in Iran and extended to the other part of the earth [5]. In Iran, pomegranate is stumbled upon as wild types and cultivated varieties [6]. Epidemiological studies have exposed that intake of red fruit juices such as grape, berry juices and pomegranate reduce the hazard of coronary heart disease, brain ailments, cancers and aging [7]. Pomegranate fruit extract crafts an excellent imbibes which contain micro and macronutrients (calcium, phosphorous, potassium and copper, manganese, zinc, iron). The anticarcinogenic, antioxidant, and immuneboosting possessions of the pomegranate recommends its numerous possible therapeutic functions [8]. Various parts of the pomegranate such as leaves, flowers and roots have worn in industry and medicine for many years [9]. Numerous markers have been used for the categorization of plants for thousands of years. Markers are those feature of an individual that can be familiar easily and be able to be used in a mapping population, additionally they can be distinctive like transmissible traits connected by the efficiently significant characteristic in the control of polygenes [10]. For the exploitation of genetic property, it is obligatory to distinguish morphological inconsistency within the compilations, for the assortment of the most appropriate variables [11]. Morphological characterization is well thought-out first step prior to starting biochemical or molecular studies [12]. For the fortitude of plant diversity morphological factors are used. In actuality morphological parameters are depended on environmental factor and agronomic performances, but morphological characterization is an extremely suggested
[12]. Morphological characteristics, particularly fruit characteristics which are stable across environments are central traits for categorizing the cultivars and also distinguish to some degree the homonymy; but they are not reliable markers for identification of synonymous genotypes [1]. Molecular markers are able to provide a valuable tool for skilled selection of preferred agronomic character as they are based on the plant genotypes and also are free from environmental factors [13]. Molecular markers such as seed storage proteins and isozymes reveal the genotype more openly, free of environmental factors. Strauss et al. [14] renowned the molecular markers into two classes, (1) molecular genetic marker or DNA based marker (2) Biochemical markers consequential of the gene expression i.e. protein based markers.

After the discovery that genes are expressed in the form of protein they are used as biochemical markers to investigate the genetic miscellany of populations. Biochemical characterization chiefly proteins based upon the partition of protein in to precise banding pattern. Seed storage protein of cereal has been investigated for more than 268 years. The biochemical molecular used for the first times was the protein based markers. Proteins are attractive for direct genetic study because they are the primary products of structural genes. Primary structure of protein will changes with change in coding base sequence of amino acid under many circumstances. Any change in sequence of amino acid of protein has obvious effects on the mobility of proteins under an electric field during electrophoresis. Isozymes have been used for decades to estimate genetic diversity [15]. They represent native enzymes that they have. Keeping in view the importance of the pomegranate, the aims of the current study was to assess the genetic diversity of cultivated and wild pomegranate 
by using the morphological and protein marker.

\section{Materials and Methods}

The plant samples were collected from different sites of Chowki. Sample of wild and cultivated pomegranate were collected from 10 different sites of Chowki, District Bhimber, Azad Kashmir.

Plants were preferred randomly for six morphological characters measurements as follows: fruit weight $(\mathrm{g})$, fruit length $(\mathrm{cm})$, fruit width $(\mathrm{mm})$, peel thickness $(\mathrm{mm})$, number of arils per fruit and leaf area $\left(\mathrm{cm}^{2}\right)$ $[16,17]$.

\section{Data Analysis}

The data analysis was done to investigate the phenotypic relationship between cultivated and wild pomegranate. The Unweighted Pair Group Method with Arithmetic Mean (UPGMA) and Principal Component Analysis (PCA) were used to assess the association between cultivated and wild pomegranate [18] with the help of computer software Minitab and Matlab.

\section{Biochemical (SDS-PAGE) Analysis}

The variation in protein was analyzed by using SDS-PAGE to scrutinize the genetic miscellany of cultivated and wild pomegranate following the method described by Payne and Lawrence, [19] with little modification.

\section{Plant material}

Mature leaves were collected from the cultivated and wild pomegranate, packed in labeled polyethylene bags and aluminum file and placed in container having liquid nitrogen. Leaf samples were brought to the laboratory of department and stored at $-80^{\circ} \mathrm{C}$ for further procedure.

\section{Protein Extraction}

Weigh $0.1 \mathrm{~g}$ leaves from each sample, grind the leaves with mortar and pestle, $1 \mathrm{ml}$ protein extraction buffer (Tris-Hcl $1.25 \mathrm{M}$ (pH 6.8), $0.03 \%$ bromophenole blue $20 \%$ SDS (sodium dodecyl sulfate) and 5\% 2mercaptoethanol, 50\% glycerol) was added to grinded sample. After overnight incubation at $40^{\circ} \mathrm{C}$ the samples were centrifuge for 10 minute at $13000 \mathrm{rpm}$. The supernatant were transferred into micro tubes and stored at $4^{0} \mathrm{C}$ until required.

Preparation Gel (10\% acrylamide gel)

The resolving gel was prepared by mixing $1.3 \mathrm{ml}$ (1.5M Tris-Hcl pH 8.8), $1.9 \mathrm{ml}$ (distilled water), $1.7 \mathrm{ml}$ (30\% acrylamide), $50 \mu \mathrm{l}(10 \%$ SDS), $50 \mu \mathrm{l}$ (APS 10\%) and $2 \mu \mathrm{l}$ TEMED was added at the end. The stacking gel was prepared by mixing $0.13 \mathrm{ml}(1 \mathrm{M}$ Tris-Hcl pH 6.8), $0.68 \mathrm{ml}$ (distilled water), $0.17 \mathrm{ml}(30 \%$ acrylamide $), 10 \mu \mathrm{l}$ (SDS $10 \%$ ), $10 \mu \mathrm{l}$ (APS 10\%) and $1 \mu \mathrm{l}$ (TEMED) at the end. After running, the gel was stained overnight with $0.2 \%$ Comassie Brilliant Blue and then distained overnight in distaining solution having acetic acid, methanol and distilled water [20].

\section{Data Analysis}

By calculating the protein bands on the gel, data matrix was prepared. In the data matrix the presence of each band was noted as 1, while the absence of every band was recorded as 0 . The data organization consisted of a binary data (0/1), which was designed to evaluate the genetic miscellany between wild and cultivated pomegranate by using Hierarchical cluster analysis with the utilization of computer software Matlab [21].

\section{Results}

The present study was undertaken to assess the variation in cultivated and wild pomegranate on the basis of morphological and biochemical traits. The results of present work were presented under the following headings:

\section{Morphological Traits}

Data analysis conferred that considerable differences were present in cultivated and wild pomegranate for six morphological traits (quantitative traits) viz; fruit weight $(\mathrm{g})$, fruit length $(\mathrm{cm})$, fruit width $(\mathrm{cm})$, peel thickness $(\mathrm{cm})$, leaf area $\left(\mathrm{cm}^{2}\right)$ and number 
of arils. Sample of cultivated pomegranate were coded as $\mathrm{Cc}_{1}, \mathrm{Cc}_{2}, \mathrm{Cc}_{3}, \mathrm{Cc}_{4} \mathrm{Cc}_{5}, \mathrm{Cc}_{6}$, $\mathrm{Cc}_{7}, \mathrm{Cc}_{8}, \mathrm{Cc}_{9}, \mathrm{Cc}_{10}$. Sample of wild pomegranate were coded a $\mathrm{Cw}_{1}, \mathrm{Cw}_{2}, \mathrm{Cw}_{3}$, $\mathrm{Cw}_{4} \mathrm{Cw}_{5}, \mathrm{Cw}_{6}, \mathrm{Cw}_{7}, \mathrm{Cw}_{8}, \mathrm{Cw}_{9}, \mathrm{Cw}_{10}$. The values were taken in triplicates which were then listed as mean values \pm standard error of means. The results of these quantitative traits were tabulated in tables $1,2,3,4,5$ respectively.

\section{Fruit weight (g)}

A lot of variation was found in fruit weight of cultivated and wild pomegranate ranging from 36 to $215 \mathrm{~g}$. The minimum mean value was $36 \mathrm{~g}$ in $\mathrm{Cw}_{9}$ and maximum mean value was $215 \mathrm{~g}$ in $\mathrm{Cc}_{3}$. The mean values of the cultivated pomegranate were $\mathrm{Cc}_{1}(196)$, $\mathrm{Cc}_{2}$ (194), $\mathrm{Cc}_{3}(215), \mathrm{Cc}_{4}(53.40), \mathrm{Cc}_{5}(83)$, $\mathrm{Cc}_{6}(68), \mathrm{Cc}_{7}$ (83.50), $\mathrm{Cc}_{8}(70.9), \mathrm{Cc}_{9}(55.10)$, $\mathrm{Cc}_{10}(53.40)$. The mean values for wild pomegranate were $\mathrm{Cw}_{1}(42), \mathrm{Cw}_{2}(40)$, $\mathrm{Cw}_{3}(50), \mathrm{Cw}_{4}(50), \mathrm{Cw}_{5}(51), \mathrm{Cw}_{6}(38), \mathrm{Cw}_{7}$ (40), $\mathrm{Cw}_{8}(42), \mathrm{Cw}_{9}$ (36), $\mathrm{Cw}_{10}$ (44) (Table 1).

\section{Fruit length (mm)}

The fruit length of both cultivated and wild pomegranate of selected site calculated by using the digital Vernier caliper and was recorded in Table 2 as mean values \pm standard error of means. The mean values for fruit length vary from $66.9-45.41 \mathrm{~cm}$ in cultivated pomegranate while in wild pomegranate the mean values were ranged from $45.65-30.00 \mathrm{~cm}$. The mean values for the cultivated pomegranate were $\mathrm{Cc}_{1}(50.45)$, $\mathrm{Cc}_{2}$ (51.15), $\quad \mathrm{Cc}_{3}(66.90), \quad \mathrm{Cc}_{4}(45.40)$, $\mathrm{Cc}_{5}(61.90), \mathrm{Cc}_{6}(55.30), \mathrm{Cc}_{7}$ (62.80), $\mathrm{Cc}_{8}(57.50), \mathrm{Cc}_{9}(46.90), \mathrm{Cc}_{10}(45.40)$. The mean values for wild pomegranate were $\mathrm{Cw}_{1}(33.65), \mathrm{cw}_{2}$ (38.55), $\mathrm{Cw}_{3}(45.65), \mathrm{Cw}_{4}$ (41.65), Cw5 (45.65) , $\mathrm{Cw}_{6}(45.00), \mathrm{Cw}_{7}$
(36.00), $\mathrm{Cw}_{8}$ (30.00), $\mathrm{Cw}_{9}(34.00), \quad \mathrm{Cw}_{10}$ (33.00). Maximum fruit length was observed in $\mathrm{Cc}_{3}$ was (66.9), minimum fruit length was recorded in $\mathrm{Cw}_{8}$ was (30.00).

\section{Fruit width (mm)}

The fruit width of both cultivated and wild pomegranate of selected site, calculated by using the digital Vernier caliper and the values were recorded in Table 3 as mean values \pm standard error of means. The mean value ranged from $11.5-64.61 \mathrm{~cm}$ (Table 3 ). The maximum mean value $64.61 \mathrm{~cm}$ was obtained in Cc3. There was clear difference between the fruit width of cultivated and wild pomegranate. The mean values for the cultivated pomegranate were $\mathrm{Cc}_{1}(47.67)$, $\mathrm{Cc}_{2}$ (67.75), $\quad \mathrm{Cc}_{3}(64.60), \quad \mathrm{Cc}_{4}(41.70)$, $\mathrm{Cc}_{5}$ (51.30), $\mathrm{Cc}_{6}(51.00), \quad \mathrm{Cc}_{7} \quad$ (54.20), $\mathrm{Cc}_{8}$ (51.00), $\mathrm{Cc}_{9}$ (44.60), $\mathrm{Cc}_{10}$ (41.70). The values recorded for wild pomegranate were $\mathrm{Cw}_{1}$ (34.35), $\mathrm{Cw}_{2}$ (32.92), $\mathrm{Cw}_{3}$ (43.25), $\mathrm{Cw}_{4}$ (11.5), Cw5 (8.45), $\mathrm{Cw}_{6}$ (30.00), $\mathrm{Cw}_{7}$ (32.00), $\mathrm{Cw}_{8}$ (25.00), $\mathrm{Cw}_{9}$ (28.00), $\mathrm{Cw}_{10}$ (34.00) (Table 3).

\section{Peel thickness (mm)}

Peel thickness of both wild and cultivated pomegranate fruits varied from 0.2 to $4.2 \mathrm{~cm}$ (Table 4). Maximum mean value was recorded as $4.2 \mathrm{~cm}$ in $\mathrm{Cc}_{5}$ and minimum value was $0.2 \mathrm{~cm}$ in $\mathrm{Cw}_{8}$ and $\mathrm{Cw}_{9}$. Mean value of both wild and cultivated pomegranate fruit peel thickness shows clear difference. The mean values for the cultivated pomegranate were $\mathrm{Cc}_{1}(0.55)$, $\mathrm{Cc}_{2}(3.3), \quad \mathrm{Cc}_{3}\left(0.3, \quad \mathrm{Cc}_{4}(4), \quad \mathrm{Cc}_{5}(4.5)\right.$, $\mathrm{Cc}_{6}(3.5), \quad \mathrm{Cc}_{7}(1), \quad \mathrm{Cc}_{8}(2.9), \quad \mathrm{Cc}_{9}(0.9)$, $\mathrm{Cc}_{10}(1.00)$. The mean values for peel thickness $(\mathrm{mm})$ of wild pomegranate were $\mathrm{Cw}_{1}$ (0.85), $\mathrm{Cw}_{2}(0.45), \mathrm{Cw}_{3}(0.45), \mathrm{Cw}_{4}$ (0.5), $\mathrm{Cw}_{5}$ (0.3), $\mathrm{Cw}_{6}(5.05), \mathrm{Cw}_{7}(0.78)$, $\mathrm{Cw}_{8}(0.2), \quad \mathrm{Cw}_{9}(0.2), \quad \mathrm{Cw}_{10} \quad$ (0.35). 
Table 1. Fruit weight (g) of cultivated and wild pomegranate

\begin{tabular}{|l|l|l|}
\hline S. No & Cultivated Pomegranate & Wild Pomegranate \\
\hline 1 & $163 \pm 0.2$ & $42.00 \pm 0.1$ \\
\hline 2 & $194 \pm 0.1$ & $40.00 \pm 0.05$ \\
\hline 3 & $215 \pm 0.05$ & $50.00 \pm 0.2$ \\
\hline 4 & $53.4 \pm 0.4$ & $50.00 \pm 0.02$ \\
\hline 5 & $83 \pm 0.1$ & $51.00 \pm 0.05$ \\
\hline 6 & $68 \pm 0.05$ & $38.00 \pm 0.04$ \\
\hline 7 & $84 \pm 0.05$ & $40.00 \pm 0.01$ \\
\hline 8 & $77 \pm 01$ & $42.00 \pm 0.1$ \\
\hline 9 & $55 \pm 0.05$ & $36.00 \pm 0.02$ \\
\hline 10 & $53 \pm 01$ & $44.00 \pm 0.2$ \\
\hline
\end{tabular}

Table 2. Fruit length ( $\mathrm{mm})$ cultivated and wild pomegranate

\begin{tabular}{|l|l|l|}
\hline S. No & Cultivated Pomegranate & Wild Pomegranate \\
\hline 1 & $50.45 \pm 0.02$ & $33.65 \pm 0.05$ \\
\hline 2 & $51.15 \pm 0.05$ & $38.55 \pm 0.1$ \\
\hline 3 & $66.9 \pm 0.06$ & $45.65 \pm 0.03$ \\
\hline 4 & $45.4 \pm 0.05$ & $41.65 \pm 0.05$ \\
\hline 5 & $61.897 \pm 0.05$ & $45.65 \pm 0.02$ \\
\hline 6 & $55.3 \pm 0.1$ & $45.00 \pm 0.05$ \\
\hline 7 & $62.8 \pm 0.1$ & $36.00 \pm 0.01$ \\
\hline 8 & $57.5 \pm 0.2$ & $30.00 \pm 0.1$ \\
\hline 9 & $46.9 \pm 0.06$ & $34.00 \pm 0.2$ \\
\hline 10 & $45.417 \pm 0.03$ & $33.00 \pm 0.05$ \\
\hline
\end{tabular}

Table 3. Fruit width (mm) of cultivated and wild pomegranate

\begin{tabular}{|l|l|l|}
\hline S. No & Cultivated Pomegranate & Wild Pomegranate \\
\hline 1 & $47.67 \pm 0.07$ & $34.35 \pm 0.04$ \\
\hline 2 & $67.75 \pm 0.05$ & $32.92 \pm 0.03$ \\
\hline 3 & $64.61 \pm 0.02$ & $43.25 \pm 0.3$ \\
\hline 4 & $41.70 \pm 0.05$ & $11.50 \pm 0.05$ \\
\hline 5 & $51.30 \pm 0.1$ & $08.45 \pm 0.1$ \\
\hline 6 & $50.96 \pm 1.05$ & $30.00 \pm 0.02$ \\
\hline 7 & $54.00 \pm 0.05$ & $32.00 \pm 0.2$ \\
\hline 8 & $51.13 \pm 0.11$ & $25.00 \pm 0.05$ \\
\hline 9 & $44.6 \pm 0.1$ & $28.00 \pm 0.05$ \\
\hline 10 & $41.7 \pm 0.1$ & $34.00 \pm 0.01$ \\
\hline
\end{tabular}


Table 4. Peel thickness ( $\mathrm{mm})$ of cultivated and wild pomegranate

\begin{tabular}{|l|l|l|}
\hline S. No & Cultivated Pomegranate & Wild Pomegranate \\
\hline 1 & $2.2 \pm 0.05$ & $0.85 \pm 0.1$ \\
\hline 2 & $3.3 \pm 0.1$ & $0.45 \pm 0.2$ \\
\hline 3 & $0.3 \pm 0.1$ & $0.45 \pm 0.2$ \\
\hline 4 & $4.0 \pm 0.1$ & $0.5 \pm 0.2$ \\
\hline 5 & $4.2 \pm 0.4$ & $0.3 \pm 0.1$ \\
\hline 6 & $3.5 \pm 0.03$ & $5.2 \pm 0.02$ \\
\hline 7 & $3.5 \pm 0.1$ & $0.78 \pm 0.1$ \\
\hline 8 & $2.9 \pm 0.05$ & $0.2 \pm 0.1$ \\
\hline 9 & $0.9 \pm 0.1$ & $0.2 \pm 0.1$ \\
\hline 10 & $0.9667 \pm 0.05$ & $0.35 \pm 0.2$ \\
\hline
\end{tabular}

\section{Number of arils}

The number of arils of fruit of cultivated and wild pomegranate varied from 180 to 495 . The highest number of arils 490 was fond in $\mathrm{CW}_{5}$ and minimum number of arils is 180 was found in $\mathrm{Cw}_{6}$. The mean values for the given parameter of cultivated pomegranate were $\quad \mathrm{Cc}_{1}(387), \quad \mathrm{Cc}_{2}(377), \quad \mathrm{Cc}_{3}(460)$, $\mathrm{Cc}_{4}(252), \mathrm{Cc}_{5}(339), \mathrm{Cc}_{6}(285), \mathrm{Cc}_{7}(372)$, $\mathrm{Cc}_{8}(294), \mathrm{Cc}_{9}(280), \mathrm{Cc}_{10}(265)$ where as the mean values for wild pomegranate were $\mathrm{Cw}_{1}(299), \mathrm{Cw}_{2}(296), \mathrm{Cw}_{3}(495), \mathrm{Cw}_{4}(300)$, $\mathrm{Cw}_{5}(490), \mathrm{Cw}_{6}(180), \quad \mathrm{Cw}_{7} \quad(200)$, $\mathrm{Cw}_{8}(280), \quad \mathrm{Cw}_{9}(294), \quad \mathrm{Cw}_{10}$ respectively.

\section{Leaf area $\left(\mathrm{cm}^{2}\right)$}

Table 6 depicted the mean value of leaf area of cultivated and wild pomegranate. The widest leaf area i.e. $9.50 \mathrm{~cm}^{2}$ was experiential in $\mathrm{Cc}_{5}$ and smallest leaf area i.e. $1.40 \mathrm{~cm}^{2}$ in $\mathrm{CW}_{4}$. A clear difference between the leaf area of wild and cultivated plant were recorded. The mean values for leaf area of cultivated pomegranate were $\mathrm{Cc}_{1}(6.52), \mathrm{Cc}_{2}(9.47), \mathrm{Cc}_{3}(5.66), \mathrm{Cc}_{4}(5.64)$, $\mathrm{Cc}_{5}\left(\right.$ 8.84), $\mathrm{Cc}_{6}(5.66), \mathrm{Cc}_{7}$ (7.20), $\mathrm{Cc}_{8}(7.95)$, $\mathrm{Cc}_{9}(7.09), \mathrm{Cc}_{10}$ (5.48). The mean values for wild pomegranate were $\mathrm{Cw}_{1}(1.79)$, $\mathrm{Cw}_{2}(1.60), \mathrm{Cw}_{3}(3.78), \mathrm{Cw}_{4}(1.50), \mathrm{Cw}_{5}$ (2.38), $\mathrm{Cw}_{6}(1.55), \mathrm{Cw}_{7}$ (2.76), $\mathrm{Cw}_{8}$ (1.5), $\mathrm{Cw}_{9}(2.14), \mathrm{Cw}_{10}$ (1.69) respectively.

Morphological characterization of wild and cultivated pomegranate basis on fruit morphology and leaf area indicated a clear difference between wild and cultivated pomegranate. The dendrogram based on morphological traits clearly revealed these results by producing two main clusters. The cluster I projected cultivated pomegranate and the cluster II comprised of wild pomegranate (Fig. 1). To access the genetic diversity among wild and cultivated pomegranate, recorded morphological data was investigated by using Principal Component Analysis (PCA) (Fig. 2). Principal Component Analysis reduces the data into four quadrants. Upper right quadrants contains $\mathrm{Cw}_{1}, \mathrm{Cw}_{2}, \mathrm{Cw}_{3}$ and $\mathrm{Cw}_{7}$ showed close relationship between these samples while the genotype $\mathrm{Cc}_{13}$ and $\mathrm{Cc}_{15}$ were projected in top left quadrants. Lower right quadrates grouped $\mathrm{Cw}_{4}, \mathrm{Cw}_{5}, \mathrm{Cw}_{10}$, $\mathrm{Cw}_{4}, \mathrm{Cw}_{10}, \mathrm{Cw}_{8}$ and $\mathrm{Cw}_{9}$ overlap each other genotype which conferred similarity in phenotypic traits whereas in lower left quadrants had grouped $\mathrm{Cc}_{16}, \mathrm{Cc}_{17}, \mathrm{Cc}_{18}, \mathrm{Cc}_{20}$ $\mathrm{Cc}_{16}$ And $\mathrm{Cc}_{17}$ Showing Similarity. Cluster analysis divides the all sample in two main groups.

Sodium Dodecyl Polyacrylamide Gel Electrophoresis (SDS-PAGE)

Morphological traits are usually worn in support of the cultivar classification; though these data could not give a precise value of genetic diversity owing to the occurrence of many alleles or environmental factors [22]. 
In view of all these disadvantages biochemical markers get more attentions towards the assessment of genetic diversity. SDS-PAGE was painstaking as powerful device for the assessment of difference and similarity between cultivated and wild pomegranate in protein bands. Genetic diversity in Wild and cultivated pomegranate for morphological traits were also checked by means of biochemical markers by using SDS-PAGE. Cluster analysis was performed in order to study the observed variation in protein banding pattern of both wild and cultivated pomegranate. The dendrogram revealed two main clusters which were clustered the wild and cultivated pomegranate to all sites. The dendrogram depicted two main clusters. The cluster-I comprised of $\mathrm{Cc}_{19}, \mathrm{Cc}_{20}, \mathrm{Cw}_{4}, \mathrm{Cw}_{6}$ and singleton $\mathrm{Cc}_{16}$. The main cluster I further divided into two sub clusters, sub cluster I and sub cluster II. Sub cluster I has $\mathrm{C}_{19}$ and $\mathrm{Cc}_{20}$, while sub cluster II has $\mathrm{Cw}_{4}$, $\mathrm{Cw}_{6}$ and singleton $\mathrm{Cc}_{16}$. The main cluster II divided into three sub clusters, sub cluster I, sub cluster II sub cluster.

Table 5. No of arils of cultivated and wild pomegranate

\begin{tabular}{|l|l|l|}
\hline S. No & Cultivated Pomegranate & Wild Pomegranate \\
\hline 1 & $387 \pm 0$ & $299 \pm 0$ \\
\hline 2 & $377 \pm 0$ & $296 \pm 0$ \\
\hline 3 & $460 \pm 0$ & $495 \pm 0$ \\
\hline 4 & $252 \pm 0$ & $300 \pm 0$ \\
\hline 5 & $339 \pm 0$ & $490 \pm 0$ \\
\hline 6 & $285 \pm 0$ & $180 \pm 0$ \\
\hline 7 & $372 \pm 0$ & $200 \pm 0$ \\
\hline 8 & $294 \pm 0$ & $280 \pm 0$ \\
\hline 9 & $280 \pm 0$ & $294 \pm 0$ \\
\hline 10 & $265 \pm 0$ & $315 \pm 0$ \\
\hline
\end{tabular}

Table 6. Leaf area $\left(\mathrm{cm}^{2}\right)$ of cultivated and wild pomegranate

\begin{tabular}{|l|l|l|}
\hline S. No & Cultivated Pomegranate & Wild Pomegranate \\
\hline 1 & $6.52 \pm 0.2$ & $1.79 \pm 0.5$ \\
\hline 2 & $9.47 \pm 0.4$ & $1.60 \pm 0.3$ \\
\hline 3 & $5.66 \pm 0.8$ & $3.78 \pm 0.9$ \\
\hline 4 & $5.66 \pm 1$ & $1.50 \pm 1$ \\
\hline 5 & $8.84 \pm 0.1$ & $2.38 \pm 1$ \\
\hline 6 & $5.66 \pm 0.12$ & $1.55 \pm 0.5$ \\
\hline 7 & $7.20 \pm 0.9$ & $2.76 \pm 0.9 .3$ \\
\hline 8 & $7.95 \pm 2$ & $1.8 \pm 0.7$ \\
\hline 9 & $7.09 \pm 0.8$ & $2.142 \pm 1$ \\
\hline 10 & $5.48 \pm 1$ & $1.69 \pm 0.9$ \\
\hline
\end{tabular}




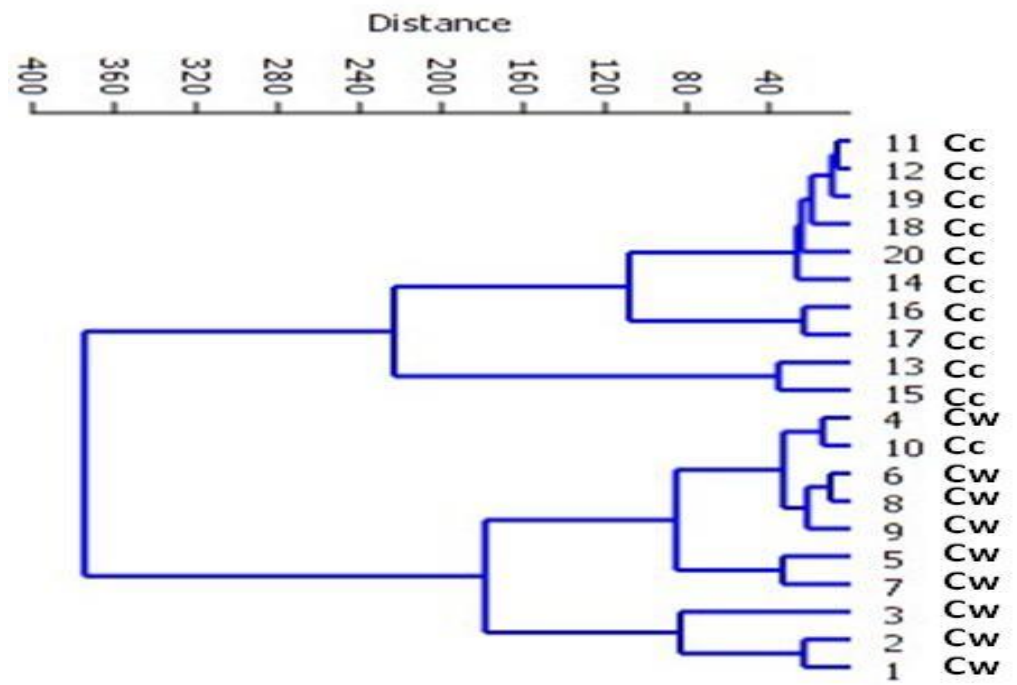

Fig. 1. Dendrogram based on morphological traits

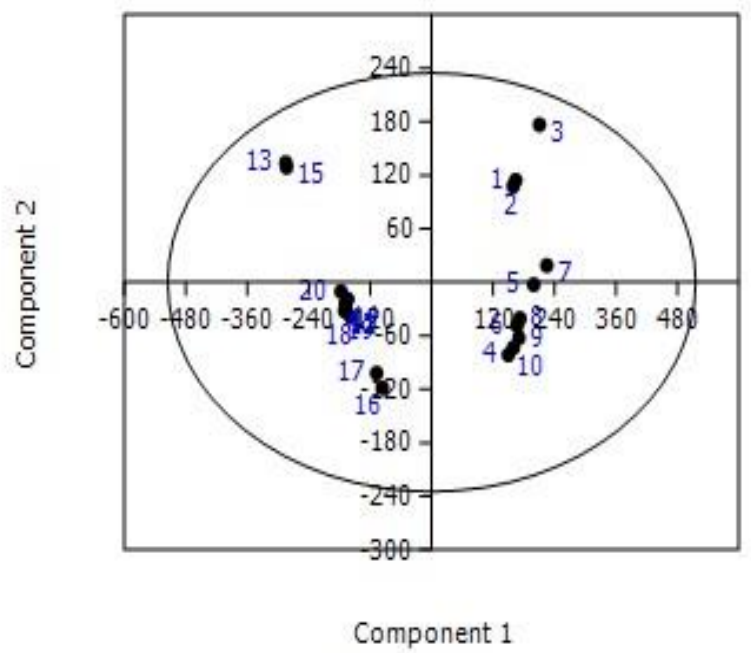

Fig. 2. Principle Component Analysis based upon morphological trait 


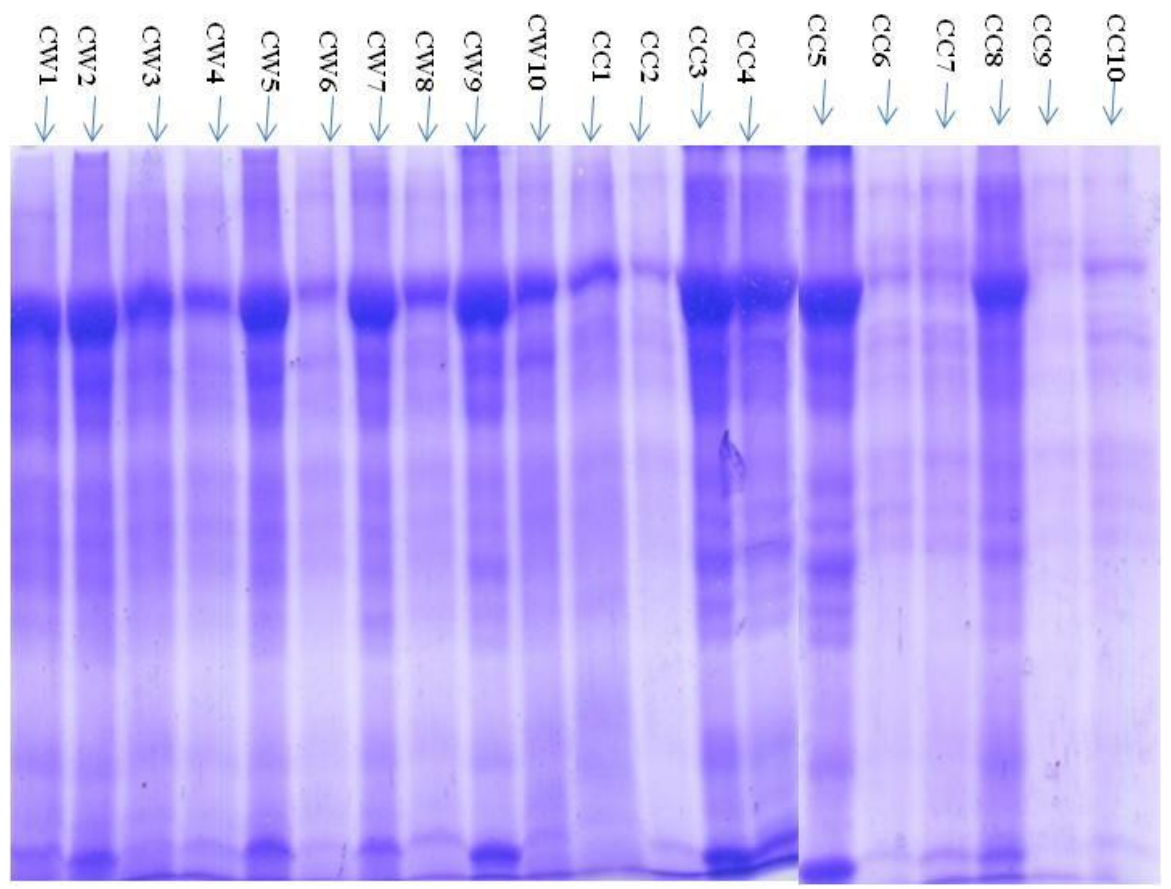

Fig. 3. SDS-PAGE electrophorogram of cultivated and wild pomegranate

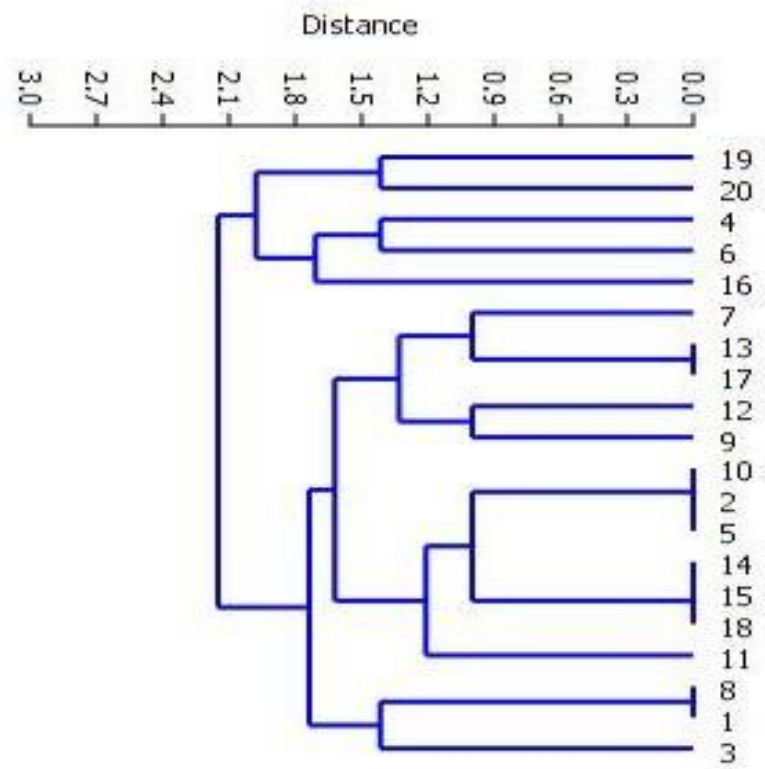

Fig. 4. Cluster analysis based upon SDS- PAGE 


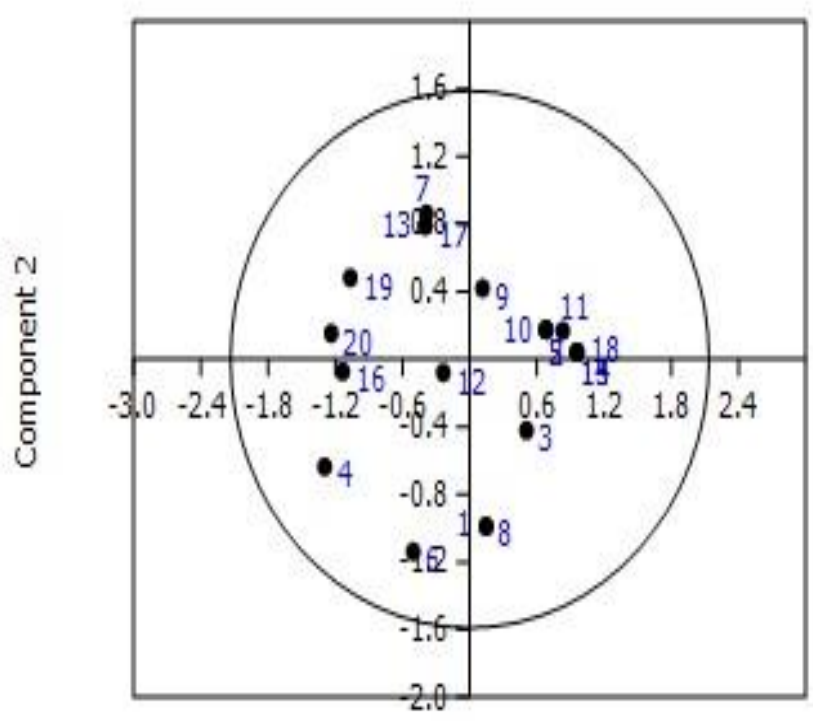

Component 1

\section{Fig. 5. Principle Component Analysis based upon SDS-PAGE}

\section{Discussion}

Morphological and biochemical markers are supporting to learn the diversity of plant genetic resources. The genetic multiplicity can be present at the species, population or even at the individual level [23]. The current study was carried out to characterized wild and cultivated pomegranate on the basis of morphological and biochemical characteristics. The results showed that fruit weight of wild and cultivated pomegranate had great variation. Weight of cultivated pomegranate fruit ranged from 53.40 to 215 $\mathrm{g}$, while in wild pomegranate fruit weight ranged from 36 to $50 \mathrm{~g}$. $\mathrm{Cw}_{3}$ and $\mathrm{Cw}_{4}$ has same weight $50 \mathrm{~g}$. These results are in harmony with the previous studies conferred that wide variation was found on fruit mass of pomegranate cultivars that ranged between 150 and $568 \mathrm{~g}[24,16]$.

In present study, the cultivated and wild pomegranate showed variability in their fruit characters especially in size of fruits. Generally the highest mean value for the fruit length $66.9 \mathrm{~mm}$ was recorded in $\mathrm{Cc}_{3}$ while minimum fruit length $30 \mathrm{~mm}$ was observed in Cw8. There was a clear difference between the length of fruit of cultivated and wild pomegranate. The length of fruit of cultivated pomegranate varied from 45.4 to $66.9 \mathrm{~mm}$. The length of fruit of wild pomegranate varied from 30 to 45.66 $\mathrm{mm}$. There was a clear difference between the width of fruit of cultivated and wild pomegranate. Width of cultivated pomegranate varied from 41.7 to $67.75 \mathrm{~mm}$ and the width of wild pomegranate ranged from 8.5 to $43.25 \mathrm{~mm}$. In some previous studies [24]. Pomegranate fruit width and length ranged from 36 to $104 \mathrm{~mm}$ and 61 to $91 \mathrm{~mm}$. The $\mathrm{Cw}_{5}$ has extremely smallest mean value $8.45 \mathrm{~mm}$ for fruit width. Peel thickness of both wild and cultivated pomegranate fruit varied from 0.2 to 4.2 $\mathrm{mm}$. Maximum mean value was $4.2 \mathrm{~mm}$ observed in $\mathrm{Cc}_{5}$ and minimum mean value was $0.2 \mathrm{~mm}$ in $\mathrm{Cw}_{8}$ and $\mathrm{Cw}_{9}$. Mean value of both wild and cultivated pomegranate 
fruit peel thickness shows clear difference. Peel thickness of the fruit ranged from 1.60 to $6.01 \mathrm{~mm}$. Number of arils is an important parameter in fruit characterization. The number of arils of fruit of cultivated and wild pomegranate varied from 180 to 495 . The maximum number of arils 490 was fond in $\mathrm{Cw}_{5}$ and minimum number of arils is 180 was found in $\mathrm{Cw}_{6}$. Table (1) and table(5) indicates that fruit weight and total number of arils were correlated with each other. The same result were also recorded by Wetzstein et al. [25] they reported that fruit weight and number of arils correlated each other. Leaf area plays an important role in transpiration, photosynthesis and productivity of plant [26]. $\mathrm{Cc}_{5}$ and $\mathrm{Cc}_{2}$ have largest leaf area (9.50) and (9.47) $\mathrm{cm}^{2}$ while $\mathrm{Cw}_{6}$ and $\mathrm{Cw}_{8}$ and (1.5) $\mathrm{cm}^{2}$ has smallest leaf area. These results were in harmony with the previous finding of Lone and Wafal, [27] who reported remarkable diversity in leaves of rosaceous plant. Both dendrogram and Principal Component Analysis (PCA) in present research work based on morphological trait revealed that cultivated and wild pomegranate were divergent. This diversity in morphological trait may be partly due to variation in environmental factors.

Characterization of cultivated and wild pomegranate based on morphological trait is unreliable because morphological traits affected by environmental conditions and needs to be confirmed on molecular level. Very sparse information is available on SDS-PAGE in favor of leaf protein for categorization of various fruit germpalsm of selected plants (cultivars and wild species). As a result it seemed that additional deviation in fruit species and their wild relatives are compulsory to evaluate variation in leaf protein. SDS-PAGE method has confirmed to be a functional tool in supporting orthodox taxonomy studies. Species are different from each other due to the difference in protein. Information about protein will help in identification of the species in addition to get the information on purity of genetic property. SDS-PAGE was taken as superior implement for the characterization of cultivated and wild pomegranate.

In this study SDS-PAGE of fresh leaves proteins was analyzed to check the genetic variability among cultivated and wild pomegranate. The electrophorogram showing proteins banding pattern of cultivated and wild pomegranate was presented in Fig. 3.

The proteins profile of every sample was determined by investigating the molecular mass of all bands. A total of 9 bands were scored in cultivated and wild pomegranate. By using the standard band of marker molecular weight of each band was calculated. The molecular weight of marker was ranged from $10-220 \mathrm{kDa}$ (Novex by life technologies) was worn for this function. On the whole low molecular weight protein band of $10 \mathrm{kDa}$ and $15 \mathrm{kDa}$ were recorded while high molecular weight protein bands were most common $60 \mathrm{kDa}$ and $70 \mathrm{kDa}$ correspondingly. Protein bands in every sample were counted and absence or presence of every band was noted and entered in a binary data matrix. Cluster analysis of proteins was performed on the outcome of SDS-PAGE to assess the diversity between cultivated and wild pomegranate. The results of cluster analysis are given in the dendrogram (Fig.4). Dendrogram inferred two main clusters along with sub clusters. In the present study maximum number of groups (15) was present in main cluster II and minimum (5) in main cluster I. Dendrogram indicated that $\mathrm{Cc}_{19}, \mathrm{Cc}_{20}, \mathrm{Cw}_{4}, \mathrm{Cw}_{6}$ and singleton $\mathrm{Cc}_{16}$ are genetically similar and was present in main cluster I. The main cluster II further divided in to three subcluster. $\mathrm{Cw}_{7}, \mathrm{Cc}_{13}, \mathrm{Cc}_{12}, \mathrm{Cw}_{9}$ and $\mathrm{Cw}_{10}$ were in sub cluster I showing 
genetic similarity. The group $\mathrm{Cw}_{2}, \mathrm{Cw}_{5}$, $\mathrm{Cc}_{14}, \mathrm{Cc}_{15}, \mathrm{Cc}_{18}$ and $\mathrm{Cc}_{11}$ were present in sub cluster II which confirmed their genetic similarity. The group $\mathrm{Cw}_{8}, \mathrm{Cw}_{1}$ and $\mathrm{Cw}_{3}$ were genetically identical to each other belonging to sub cluster III. This cluster of groups exhibited the highest diversity with other clusters. The dendrogram as a whole show low heterogeneity because most of the cultivated and wild pomegranate was in the same cluster. These results were in harmony with the previous conclusion of Shuaib et al. [20] who reported that there was low degree of heterogeneity in different wheat varieties although they show different protein banding pattern.

In previous study Siddiqui and Naz [28] also reported low level of heterogeneity among wheat genotypes. These results are in accordance with the conclusion of Masood et al, (1994) who revealed by using SDSPAGE electrophoregrams of seed storage protein that Inter and Intra- specific variation were present in wheat, barley and their wild relatives. In this study results of biochemical trait and morphological traits was not chiefly match with each other.

In previous studies Saleem et al, [22] reported that the value of genetic remoteness based on the morphological traits was typically superior (23.49) than genetic markers (0.688), which may reveal the consequence of the environment on morphological traits. Semagan, [29] recommended two reasons for little relationship among morphological markers and genetic markers(1) molecular markers covers a huge quantity of genome in contrast to morphological traits. (2) Morphological characters are more subjected to artificial selection as compared to molecular markers.

\section{Conclusion}

On the basis of present investigations it is concluded that great genetic diversity among morphological and biochemical traits of wild and cultivated pomegranate were present. The miscellany of protein bands are pinpointing of genetic diversity and may be precious in categorization of the wild and cultivated pomegranate. The protein bands model established a affiliation between wild and cultivated pomegranate. The protein bands pattern reveal a rather low genetic diversity among the wild and cultivated pomegranate signifying a higher extent of genetic similarity among them. Furthermore, although morphological markers were used and slight variation were detected between wild and cultivated, therefore there is a need to characterize of wild and cultivated pomegranate at molecular level in detail. Integrating morphological and protein based markers with DNA-based markers in pomegranate may offer the greatest prospect in the future.

\section{Authors' contributions}

Conceived, designed the experiments and analyzed the data: MA Hussain, performed the experiments: $\mathrm{N}$ Akram, Contributed reagents/materials/analysis tools and wrote the paper: I Ali.

\section{References}

1. Mars M and Marrakchi M (1999). Diversity of pomegranate (punica granatuml.) germplasm in tunisia. Genet. Res. Crop Evol. 46:461-46.

2. Madihassan S (1984). Outline of the Beginning of Alchemy and Its Antecedents. Ameri. J. Chine. Med. 12(1):32-42.

3. Aviram M \& Dornfeld L (2001). Pomegranate juice consumption inhibits serum angiotensin converting enzyme activity and reduces systolic blood pressure. Atherosclerosis 158:195 -198.

4. Seeram NP, Henning SM, Zhang Y, Suchard M, Li Z \& Heber D (2006). Pomegranate Juice Ellagitannin Metabolites are Present in Human Plasma and Some Persist in Urine for 
up to 48 hours. J. Nutriti. 136(10):2481-2485.

5. Levin GM (1994). Pomegranate (Punica granatum L.) plant genetic resources in Turkmenistan. Plant Gene. Res. Newslet. 97:31-36.

6. Al-Said FA, Opara LU \& Al-Yahyai RA (2009). Physico-chemical and textural quality attributes of pomegranate cultivars (Punica granatum L.) grown in the Sultanate of Oman. J. Food Eng. 90:129-134.

7. Prior RL \& Cao G (2000). Antioxidant Phytochemicals in Fruits and Vegetables: Diet and Health Implications. Horti. Sci. 35(4):588592.

8. Kaplan M, Hayek T, Raz A, Coleman R, Dornfeld L, Vaya J \& Aviram M (2001). Pomegranate juice supplementation to atherosclerotic mice reduces macrophage lipid peroxidation, cellular cholesterol accumulation and development of atherosclerosis. J. Nutr. 131 (8): 2082-89.

9. Feng Y, Chen D, Ting S, M, Li Y \& Zhan H (1998). Assessment and utilization of pomegranate cultivars recourses. J. Fruit Sci. 15(4):370373.

10. Beckman JS \& Soller M (1986). Restriction fragment length polymorphism and genetic improvement of agricultural species. Euphytica. 3:111-24.

11. Giraldo E, Lopez CM \& Hormaza JI (2010). Selection of the most discriminating morphological qualitative variables for characterization of fig germplasm. J. Amer. Soc. Hort. Sci. 135:240-249.

12. Hoogendijk M \& Williams DE (2001). Characterizing the genetic diversity of home garden crops: some examples from the Americas. In: Proceedings of the Second International Home Gardens Workshop: Contribution of Home Gardens and In Situ Conservation of Plant Genetic Resources in Farming Systems (Eds. JW Watson, PB Eyzaguirre), IPGRI, Germany, :34-40.

13. Franco J, Crossa J, Ribaut JM, Betran J, Warburton ML \& Khairallah M (2001). A method for combining molecular markers and phenotypic attributes for classifying plant genotypes. Theor. Appl. Genet. 103:944-952.

14. Strauss SH, Bonsquet J, Hipkins VD \& Hong YP (1992). Biochemical and molecular genetic markers in biosystematic studies of forest trees. New Forests. 6:125-158.

15. Tanksley SD \& Orton TJ (1983). Isozymes in Plant Genetics and Breeding Elsevier, Amsterdam. 1(2): $561-472$.

16. Tehranifar A, Mehdi Z, Behnam E, \& Zahra N (2010). Physicochemical Properties and Antioxidant activities of pomegranate fruit (Punica granatum) of different cultivars grown in Iran. Pak. J. Bot. 42(3):1797-1805.

17. Shashikala SK (1996). Genetics and plant breeding. College of agriculture, Dharwad university of agriculture sciences, Dharwad -580 005.

18. Sneath PHA \& Sokal RR (1973). Numerical Taxonomy:The principles and practices of numerical classification. W. F and Co. Freeman, San Francisco.

19. Payne PI \& Lawrence GJ (1983). Cataloge of allies for the complex gene loci, Glu-A1, Glu-B1 and Glu-D1 which code for the high-molecularweight subunits of the glutenin in hexaploid wheat. Cereal Res. Commun. 11: 29-35.

20. Shuaib M, Jamal M, Akbar H, Khan I \& Khalid R (2010). The Evaluation of 
wheat by polyacrylamide gel electrophorosis. Afri. J. biotech. 9(2):243-247.

21. Shuaib M, Alam Z, Zahir A, Waqar Ali, Taufiq A \& Ikhtiar K (2007). Characterization of wheat varieties by seed storage protein electrophoresis. Afric. J. Biotech. 6 (5):497-500.

22. Saleem KFM, Al-Zanaty AM \& Esmail RM (2008). Assessing Wheat (Triticum aestivum L) Genetic Diversity using morphological characters and microsatallite markers. W. J. A. S. 4(5):538-544.

23. Lakshmikumaran M (2000). Application of molecular markers for assessment of genetic diversity. In: Abstract and Souvenir, National Symposium on Prospects and Potentials of Plant Biotechnology in India in the 21st Century and $23^{\text {rd }}$ Annual Meeting of PTCA (I): Jodhpur, 188:18-21.

24. Al-Maiman SA \& Dilshad A (2002). Changes in physical and chemical properties during pomegranate (Punica granatum L.) fruit maturation. J. Food Chem. 76:437-441.

25. Wetzstein HY, Zibin Z, Nadav R \& Michael EW (2011). Characterization of attributes related to fruit size in Pomegranate. Hort. Sci. 46(6), 908912.

26. Goudriaan J \& Van Laar HH (1994). Modelling potential crop growth processes. Dordrecht, The Netherlands: Kluwer Academic Publishers.

27. Lone AF \& Wafal BA (2000). Varietal diversity in the germplasm of cherries under cultivation in Kashmir. In: Environmental biodiversity and conservation, Khan MA, Farooq S (eds). APH Publ. New Delhi, 319-340.

28. Siddiqui MF \& Naz N (2009). Protein landmarks for diversity assessment in wheat genotypes. Afric. J. Biotech. 8(9): 1855 .

29. Semagan K (2002). Genetic relationship among tenendod types as revealed by the combination of morphological, RAPD and AFLP markers. Hereditas. 137:149-156. 